Joyful Learning Journal

\title{
MEDIA APLIKASI BELAJAR CERDAS BERBASIS ANDROID DENGAN MODEL TPS PADA MUPEL IPS
}

\author{
Peggi Utami ${ }^{\bowtie}$, Dra. Arini Estiastuti, M.Pd
}

Jurusan Pendidikan Guru Sekolah Dasar, Fakultas Ilmu Pendidikan, Universitas Negeri Semarang, Indonesia

\section{Info Artikel Abstrak}

Sejarah Artikel:

Diterima Juli 2020

Disetujui Agustus 2020

Dipublikasikan Septembe 2020

Keywords:

based on android; media;

students learning outcomes
Observasi dikelas V SD Negeri Krapyak menunjukkan bahwa guru belum memanfaatkan media pembelajaran khususnya berbasis IT, yang berpengaruh pada rendahnya hasil belajar siswa. Sehingga dilakukan pengembangan media Aplikasi Belajar Cerdas berbasis android. Penelitian ini bertujuan menguji kelayakan dan keefektifan media pembelajaran Aplikasi Belajar Cerdas berbasis android pada mupel IPS SD Negeri Krapyak. Jenis penelitian ini adalah penelitian pengembangan (R\&D), dengan subjek penelitian siswa kelas V SD Negeri Krapyak. Teknik pengumpulan data menggunakan teknik tes, observasi, wawancara, angket dan dokumentasi. Teknik analisis data menggunakan deskriptif persentase, uji normalitas, uji t-tes dan uji n-gain. Hasil penelitian ini menunjukkan bahwa (1) media Aplikasi Belajar Cerdas berbasis android telah dikembangkan; (2) media Aplikasi Belajar Cerdas berbasis android dinyatakan sangat layak oleh ahli media dan ahli materi; (3) media Aplikasi Belajar Cerdas berbasis android terbukti efektif meningkatkan hasil belajar siswa pada ranah kognitif dengan uji $t$-test paired sample test dan $\mathrm{n}$-gain. Berdasarkan hasil penelitian, dapat disimpulkan bahwa Aplikasi Belajar Cerdas berbasis android dinyatakan layak dan efektif meningkatkan hasil belajar IPS siswa kelas $\mathrm{V}$.

\begin{abstract}
Observation in 5th grade of SD Negeri Krapyak shows that the teacher have not utilized learning media especially IT-based. As a consequence, students learning outcomes were not maximal. Based on that observation, the development media Application Smart Learning based on android is carried out. This study aims to test the feasibility and effectivity of the Application Smart Learning based on android, on social science studies in SD Negeri Krapyak. This type of research is a research and development $(R \& D)$, with the subject of research is students of fifth grade at SD Negeri Krapyak. Data collection techniques used test techniques, observation, interviews, questionnaires and documentation. Data analysis techniques used descriptive percentages, normality test, $t$-test and n-gain test. The results showed that (1) media Application Smart Learning based on android had been developed; (2) media Application Smart Learning based on android is clarified very feasible by experts; (3) media Application Smart Learning based on android is proven to be effective in increasing student learning outcomes in cognitive domain with $t$ test paired sample and n-gain. Based on the results of the study, it can be concluded that the Application Smart Learning based on android is feasible and effective to improve the students learning outcomes on social science studies.
\end{abstract}

\footnotetext{
Alamat korespondensi:

Karyomukti, RT/RW 02/03, Kesesi, Kabupaten Pekalongan.

E-mail: peggi.utami@gmail.com
}

ISSN 2252-6366 


\section{PENDAHULUAN}

Pendidikan adalah faktor yang sangat penting bagi setiap manusia untuk membangun serta mengembangkan potensi pada dirinya. Seperti disebutkan pada pasal 1 ayat 1 dalam Undang-Undang Republik Indonesia Nomor 20 Tahun 2003 tentang Sistem Pendidikan Nasional, bahwa pendidikan adalah usaha sadar yang dilakukan secara sistematis bertujuan untuk mengembangkan potensi dalam diri agar mempunyai kecerdasan bukan hanya kecerdasan intelektual melainkan juga dalam keagamaan, kepribadian serta keterampilan. Maka dari itu pendidikan haruslah bersifat dinamis untuk memaksimalkan potensi dalam diri peserta didik ara mampu menyesuaikan dengan perkembangan ilmu pengetahuan.

Untuk mencapai sistem pendidikan yang dinamis, kurikulum yang diterapkan disesuaikan dengan perkembangan ilmu pengetahuan. Sejalan dengan perkembangan kurikulum, Permendiknas RI Nomor 22 Tahun 2006 menegaskan bahwa substansi mata pelajaran IPS untuk SD/MI dan SMP/MTs/SMPLB adalah IPS Terpadu yang merupakan integrasi dari berbagai cabang ilmuilmu sosial. IPS merupakan muatan yang mengalami pembauran dari bidang atau ilmu lain tetapi dalam ruang lingkup yang sama yaitu sosial yang dipadukan dari setiap bidang satu ilmu itu sehingga menjadi satu muatan (Ansori \& Fithri, 2019). IPS mulai diajarkan pada tingkat pendidikan dasar dari kelas IV sampai kelas VI, dengan ruang lingkup materi yang tercantum dalam Permendikbud RI No 21 Tahun 2016 tentang Standar Isi Pendidikan Dasar dan Menengah yaitu: (1) manusia, tempat, dan lingkungan (2) waktu, keberlanjutan, dan perubahan (3) sistem sosial dan budaya (4) perilaku ekonomi dan kesejahteraan. Sementarapada Permendikbud RI No 22 Tahun 2016 tentang Standar Proses Pendidikan Dasar dan Menengah dituliskan bahwa proses pembelajaran bukan hanya saat kegiatan pembelajaran saja melainkan meliputi perencanaan pembelajaran, pelaksanaan pembelajaran, penilaian proses dan hasil pembelajaran, serta pengawasan proses pembelajaran. Dengan adanya Standar Isi dan Standar Proses pada pembelajaran IPS, peserta didik diharapkan dapat menjadi warga negara Indonesia yang mempunyai jiwa demokratis, patriotis, serta bertanggung jawab. Tujuan utama dari pembelajaran muatan IPS yaitu mengembangkan potensi dalam diri peserta didik agar mampu memahami masalah sosial yan terjadi di masyarakat, mempunyai pemikiran positif terhadap segala perbaikan dari ketimpangan sosial, serta mampu mencari solusi setiap masalah yang menimpa diri sendiri maupun menimpa masyarakat (Trianto, 2015).

Terdapat permasalahan yang menjadi kendala dalam mencapai tujuan pembelajaran IPS. Berdasarkan hasil pra- penelitian dengan wawancara serta observasi yang dilaksanakan di kelas VA SD Negeri Krapyak, bahwa masalah yang dihadapi dalam pembelajaran IPS antara lain: (1) Media pembelajaran khususnya media berbasis IT kurang dimanfaatkan sepenuhnya oleh guru. (2) Terbatasnya buku referensi/bahan ajar yang digunakan oleh siswa. (3) Metode pengajaran yang konvensional. (4) Kurangnya variasi stimulus dan pemusatan perhatian yang dilakukan guru dalam pembelajaran. (5) Siswa kesulitan dalam memahami materi IPS. (6) Kurang maksimalnya hasil belajar siswa pada mupel IPS, dengan KKM 70 terdapat 37\% siswa tidak memenuhi KKM.

Perkembangan siswa pada usia sekolah dasar berada pada tahap operasional konkrit, yaitu tahap dimana mereka akan lebih memahami sesuatu dalam bentuk konkrit dari pada abstrak. Sehingga penggunaan media merupakan salah satu faktor yang sangat penting dalam pembelajaran, sebagai penyalur pesan dari sesuatu yang abstrak menjadi hal konkrit. Gunawan (2014) berpendapat bahwa media pembelajaran merupakan segala sesusatu yang digunakan guru dalam pembelajaran, sehingga dapat meningkatkan kualitas dalam pembelajaran dan mampu mencapai kompetensi pembelajaran. Ahmadi, dkk (2017) juga menerangkan media pembelajaran berfungsi sebagai sumber belajar yakni sebagai penyalur, penyampai, atau penghubung.

Pada masa sekarang, penggunaan teknologi sudah menjadi hal yang biasa. Ditandai dengan muculnya era Revolusi Industri 4.0 yang merupakan revolusi teknologi digital. Hoedi Prasetyo \& Sutopo (2018) mengartikan Revolusi Industri 4.0 sebagai era industri di mana seluruh subjek yang ada di dalamnya dapat saling berkomunikasi kapan saja dan dimana saja dengan berlandaskan pemanfaatan teknologi internet guna mencapai tujuan bersama. Beberapa pakar industri menjelaskan perkembangan industri di dunia sudah mencapai Sebagai perkembangan lanjut dari gelombang-gelombang Revolusi Industri sebelumnya, karena proses industri terkait revolusi digital sudah memasuki abad 21 . Seperti yang ditegaskan oleh Sulistyorini, dkk (2018) bahwa paradigma pembelajaran abad 21 menekankan kepada kemampuan siswa berpikir kritis, untuk mampu menghubungkan ilmu dengan dunia nyata, menguasai teknologi informasi komunikasi, dan berkolaborasi. Hal ini menjadi alasan penembangan media pembelajaran berbasis teknologi yang menarik 
dan mudah digunakan bagi peserta didik. Sehingga diharapkan dengan membawa teknologi yang terbaru dalam pembelajaran dapat menciptakan suasana pembelajaran yang lebih menyenangkan.

Untuk lebih memaksimalkan proses pembelajaran, maka model pembelajaran yang digunakan haruslah inovatif. Menurut Suherman (2003) model pembelajaran merupakan suatu pola interaksi antara peserta didik dengan pendidik yang diimplementasikan dalam pelaksanaan kegiatan pembelajaran untuk mencapai tujuan serta kompetensi pembelajaran. Peneliti menggunakan model TPS (Think-Pair-Share) agar dapat mendukung pembelajaran dengan media berbasis android. Salah satu keunggulan dari model TPS yaitu mampu melibatkan peserta didik aktif selama proses pembelajaran, sehingga diharapkan meningkatkan prestasi hasil belajar. Seperti oleh Sri Sumarni (2016) bahwa terdapat perbedaan konsep pemahaman pada materi pembelajaran yang berpengaruh pada hasil belajar siswa. Hasil belajar adalah suatu bentuk perubahan pada seseorang yang sudah melalui proses belajar, tidak hanya menyangkut pengatahuan tetapi juga keterampilan dan penghayatan dalam diri seseorang tersebut (Muthoharoh, 2017).

Tujuan penelitian ini adalah untuk:(1) mengembangkan media Aplikasi Belajar Cerdas berbasis android; (2) menguji kelayakan media Aplikasi Belajar Cerdas berbasis android pada pembelajaran IPS kelas V; (3) menguji keefektifan media Aplikasi Belajar Cerdas berbasis android pada pembelajaran IPS kelas V.

\section{METODE PENELITIAN}

Penelitian ini merupakan penelitian Research and Development, yaitu penelitian yang digunakan untuk menghasilkan produk tertentu dan menguji keefektifan produk tersebut (Sugiyono, 2016). Dengan langkah- langkah penelitian berpedoman pada Sugiyono (2016) yang dikembangkan sesuai dengan kebutuhan, yaitu potensi masalah, pengumpulan data, desain produk, validasi desain, revisi desain, uji coba produk, revisi produk, uji pemakaian produk, dan produksi masal.

Sumber penelitian berasal dari siswa, guru, dan pakar ahli. Subjek utama dari penelitian yaitu siswa kelas V SD Negeri Krapyak. Terdapat 12 siswa kelas VC yang diambil berdasarkan teknik sampling purposive, yaitu teknik penentuan sampel dengan pertimbangan tertentu, serta 30 siswa kelas VA dengan menggunakan sampel jenuh.

Variabel bebas dalam penelitian adalah media pembelajaran Aplikasi Belajar Cerdas berbasis android, dan variabel terikat adalah hasil belajar ranah kognitif kelas V SD Negeri Krapyak pada mupel IPS. Teknik pengumpulan data yang digunakan dalam penelitian ini adalah wawancara, dokumentasi, angket dan tes berupa soal pilihan ganda. Data yang diambil dalam penelitian ini terdiri atas data penilaian kelayakan Aplikasi Belajar Cerdas berbasis android oleh ahli media dan ahli materi, data respon siswa dan guru terhadap Aplikasi Belajar Cerdas berbasis android, serta hasil belajar IPS siswa. Teknik analisis data yang digunakan adalah deskriptif presentase dengan skala Likert, uji normalitas, uji t-tes, dan uji ngain.

\section{HASIL PENELITIAN DAN PEMBAHASAN}

Penelitian ini menghasilkan produk berupa media pembelajaran Aplikasi Belajar Cerdas berbasis android. Hasil penelitian dan pembahasan mencakup pengembangan, kelayakan, dan keefektifan Aplikasi Belajar Cerdas berbasis android.

\section{Pengembangan Aplikasi Belajar Cerdas Berbasis Android}

Aplikasi Belajar Cerdas berbasis android dikembangakan sesuai dengan hasil analisis kebutuhan guru dan siswa. Media Aplikasi Belajar Cerdas berbasis android diterapkan pada pembelajaran IPS kelas V Semester II Tema 7 materi kedatangan bangsa Eropa dengan indikator: 3.4.1) menganalisis faktor penyebab kedatangan bangsa Eropa di Indonesia; 3.4.2) menyebutkan rute perjalanan bangsa Eropa ke Indonesia; dan 3.4.3) menjelaskan peristiwa kedatangan bangsa Eropa di Indonesia. Media Aplikasi Belajar Cerdas berbasis android juga dilengkapi dengan gambar animasi, video, kuis serta soal evaluasi yang berkaitan dengan materi.

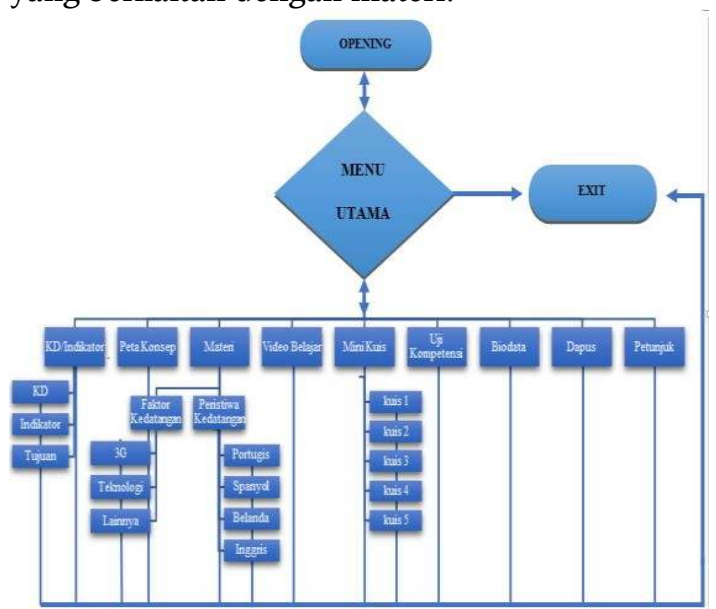

Gambar 1 Bagan alur pengembangan media Aplikasi Belajar Cerdas berbasis android 


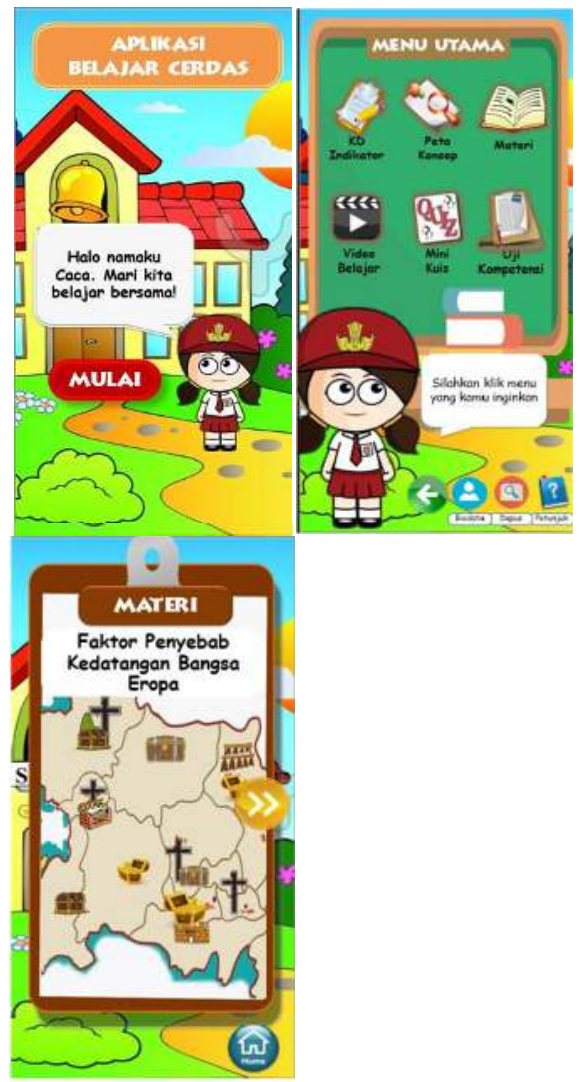

Gambar 2 Tampilan Aplikasi Belajar Cerdas berbasis android

\section{Kelayakan Aplikasi Belajar Cerdas Berbasis Android}

Penilaian kelayakan Aplikasi Belajar Cerdas berbasis android dilakukan dengan menggunakan instrumen Penilaian Buku Teks Pelajaran tahun 2014 dari BSNP yang dimodifikasi. Penilaian kelayakan dilakukan oleh validator ahli: (1) ahli media adalah Sony Zulfikasari, S.Pd., M.Pd., (2) ahli materi adalah Dra. Arini Estiastuti, M.Pd. Serta dengan mengumpulkan respon siswa dan guru setelah menggunakan media.

Tabel 1 Penilaian Kelayakan oleh Validator Ahli

\begin{tabular}{llcc}
\hline No & \multicolumn{1}{c}{ Parameter } & Ahli Media & Ahli Materi \\
\hline 1. & $\begin{array}{l}\text { Skor yang } \\
\text { diperoleh }\end{array}$ & 47 & 59 \\
2. & Skor maksimal & 48 & 60 \\
3. & Persentase & $98 \%$ & $98 \%$ \\
4. & Kriteria & Sangat Layak Sangat Layak \\
\hline
\end{tabular}

Penilaian menggunakan lembar angket validasi yang berisi butir penilaian berdasarkan aspek penilaian. Aspek penilaian validasi media adalah : 1) aspek kesesuaian media, 2) aspek mutu teknis, dan 3) aspek kemudahan penggunaan. Sedangkan aspek penilaian validasi materi meliputi: 1) kesesuaian isi, 2) kelayakan materi, 3) kesesuaian bahasa, dan 4) kelayakan penyajian.

$$
\text { Media direvisi berdasarkan }
$$

rekomendasi atau saran yang diberikan oleh ahli media dan ahli materi. Revisi produk bertujuan untuk memperbaiki media Aplikasi Belajar Cerdas berbasis android sesuai dengan saran yang diberikan oleh ahli sebelumnya. Setelah revisi media selesai, maka uji produk dilaksanakan pada dua kelas, yaitu kelas uji coba produk skala kecil dengan 12 siswa kelas VC dan uji pemakaian produk skala besar dengan 30 siswa kelas VA SD Negeri Krapyak. Kemudian pengisian angket untuk mengetahui respon dari siswa dan guru setelah menggunakan media.

Tabel 2 Penilaian Kelayakan dengan Respon Siswa dan Guru

\begin{tabular}{clcc}
\hline No & $\begin{array}{l}\text { Kelas Uji } \\
\text { Coba }\end{array}$ & Siswa & Guru \\
\hline 1. & Skala Kecil & $100 \%$ & $100 \%$ \\
2. & Skala Besar & $96 \%$ & $90 \%$ \\
3. & Kriteria & $\begin{array}{r}\text { Sangat } \\
\text { Layak }\end{array}$ & Sangat Layak \\
\hline
\end{tabular}

Dari perolehan nilai validasi dan respon penggunaan, dapat disimpulkan bahwa media Aplikasi Belajar Cerdas berbasis android sangat layak diterapkan dalam pembelajaran kelas $\mathrm{V}$ pada mupel IPS materi kedatangan bangsa Eropa.

\section{Keefektifan Aplikasi Belajar Cerdas Berbasis Android}

Keefektifan penggunaan media Aplikasi Belajar Cerdas berbasis android dapat dilihat dari hasil belajar siswa pada ranah kognitif. Pada ranah kognitif, hasil belajar siswa diukur dengan tes tertulis berupa pretest dan posttest yang dilakukan sebelum dan setelah pembelajaran menggunakan media Aplikasi Belajar Cerdas berbasis android.

Peningkatan hasil belajar siswa diukur dengan menggunakan uji t-test paired sample test dan n-gain berbantuan program SPSS 22 . Berdasarkan hasil output uji t-test, untuk uji coba produk skala kecil terhadap 12 siswa kelas VC SD Negeri Krapyak didapatkan hasil sig (2tailed) $=0,000$ dan uji t-test terhadap 30 siswa kelas VA SD Negeri Krapyak pada uji pemakaian produk mendapat hasil sig (2-tailed) $=0,000$. Karena nilai probabilitas Sig $\leq$ nilai probabilitas $(0,05)$ yaitu $0,000 \leq 0,05$, maka Ho ditolak dan Ha diterima. Sedangkan untuk uji ngain, pada skala kecil nilai n-gain adalah 0,60 dengan kriteria sedang dan pada skala besar nilai n-gain adalah 0,59 termasuk dalam kriteria 
sedang. Dari uji t-test paired sample test dan n-gain dapat disimpulkan bahwa terdapat keefektifan dan peningkatan nilai yang signifikan pada hasil belajar IPS antara sebelum dan sesudah menggunakan media Aplikasi Belajar Cerdas berbasis android dikelas V SD Negeri Krapyak. Seperti yang dijelaskan pada penelitian oleh Zatulifa dkk (2018) bahwa penggunaan aplikasi dalam pembelajaran Bahasa Inggris dapat dikatakan efektif dengan rata-rata postest yang dihasilkan yaitu 77,56. Serta persentase ketuntasan mencapai 87\%. Penggunaan aplikasi juga lebih efisien 45 menit dari pada penggunaan buku atau media pembelajaran biasa. Serta penelitian oleh Moh. Syadidul Itqan (2018) menghasilkan produk berupa game android yang efektif digunakan untuk meningatkan minat belajar siswa.

Penggunaan media Aplikasi Belajar Cerdas berbasis android dimasukkan dalam pembelajaran dengan model TPS (Think- PairShare) yang memiliki arti berpikir, berpasangan, berbagi. Model ini dirancang untuk mempengaruhi pola interaksi peserta didik dengan memperkenalkan waktu berpikir (Shoimin, 2014). Salah satu keunggulan dari model TPS yaitu mampu melibatkan peserta didik aktif selama proses pembelajaran, sehingga diharapkan meningkatkan prestasi hasil belajar. Pada penelitian yang berjudul "Utilising the Think-Pair-Share Technique in the Learning of Probability" (Lee, Li, dan Shahrill, 2018), menunjukkan bahwa terdapat peningkatan nilai tes siswa dan para siswa tersebut mampu mempertahankan pengetahuan mereka setelah jangka waktu tertentu. Serta penelitian oleh Nurazizah dan Wuryandari (2019) menunjukkan hasil bahwa terdapat pengaruh yang positif dan signifikan antara model Think Pair Share terhadap kerja sama siswa.

\section{SIMPULAN DAN SARAN}

Berdasarkan hasil penelitian, maka dapat disimpulkan bahwa Aplikasi Belajar Cerdas berbasis android yang dikembangkan dinyatakan layak dan efektif dapat meningkatkan hasil belajar IPS siswa kelas V. Saran penelitian ini yaitu Aplikasi Belajar Cerdas berbasis android dapat digunakan sebagai media pembelajaran alternatif dalam pembelajaran IPS untuk menambah variasi sehingga pembelajaran menjadi lebih bermakna, bervariasi dan menyenangkan.

\section{UCAPAN TERIMAKASIH}

Peneliti mengucapkan terimakasih kepada kedua orang tua yang selalu memberikan dukungan kepada peneliti.
Terimakasih kepada Dra. Arini Estiastuti, M.Pd. sebagai dosen pembimbing, Dra. Munisah, M.Pd sebagai mitra bestari I, Farid Ahmadi, S.Kom., M.Kom., Ph.D sebagai mitra bestari II, Desi Wulandari, S.Pd., M.Pd sebagai penyunting abstrak bahasa Inggris yang telah memberikan bimbingan dan koreksi pada artikel penelitian ini.

\section{DAFTAR PUSTAKA}

Ahmadi, F., Sutaryono, Witanto, Y., \& Ratnaningrum, I. (2017). Pengembangan Media Edukasi "Multimedia Indonesian Culture" (MIC) sebagai Penguatan. Jurnal Penelitian Pendidikan, 34(2), 127-136.

Ansori, I., \& Fithri. (2019). Hubungan Minat Belajar dan Disiplin Belajar Terhadap Prestasi Belajar Muatan Pembelajaran IPS. SEMINAR NASIONAL PASCASARJANA UNNES, 1(1), 11521156.

Fitriani, K., \& Wuryandari, W. (2019). Pengaruh Model Kooperatif Tipe Think Pair Share Terhadap Kerja Sama Siswa. Jurnal Civics: Media Kajian Kewarganegaraan, 16(1), 80-88

Gunawan, Rudy. 2014. Pengembangan Kompetensi Guru IPS. Bandung: Alfabeta.

Itqan, M. S. (2018). Pendekatan Game Android Untuk Meningkatkan Minat Belajar Matematika Siswa Sekolah Dasar. Jurnal EduMatSains, 2(2), 161-170.

Lee, C., Li, H.-C., \& Shahrill, M. (2018). Utilising the Think-Pair-Share Technique in the Learning of Probability. International Journal on Emerging Mathematics Education, 2(1), 49.

Muthoharoh, N. B. (2017). Pengaruh Model Pembelajaran Kooperatif "Think Pair Share" terhadap Hasil Belajar Bahasa Inggris. SAP (Susunan Artikel Pendidikan), 2(1), 33-42.

Nurdin, Syafruddin \& Adrianto. 2016. Kurikulum dan Pembelajaran. Jakarta: Rajagrafindo Persada.

Permendikbud RI No 21 Tahun 2016 tentang Standar Isi Pendidikan Dasar dan Menengah. 
Permendikbud RI No 22 Tahun 2016 tentang Standar Proses Pendidikan Dasar dan Menengah.

Prasetyo, Hoedi, \& Sutopo, W. (2018). Industri 4.0: Telaah Klasifikasi Aspek dan Arah Perkembangan Riset. J@ti Undip: Jurnal Teknik Industri, 13(1), 17-26.

Sugiyono. 2016. Metode Penelitian Pendidikan: Pendekatan Kuantitatif, Kualitatif dan $R n D$. Bandung: Alfabeta.

Sulistyorini, S., Harmanto, Abidin, Z., \& Jaino. (2018). Pengembangan Lembar Kerja Peserta Didik (LKPD) Tematik Terpadu Mengintegrasikan Penguatan Pendidikan Karakter (PPK) dan Literasi Siswa Sd Di Kota Semarang. Jurnal Kreatif, 8(4), 138-147.
Sumarni, S. (2016). Think Pair Share Effect of Understanding the Concept and Achievement. Proceeding The 2nd International Conference On Teacher Training and Education Sebelas Maret University, 2(1), 783-787.

Trianto. 2015. Model Pembelajaran Terpadu. Jakarta: Bumi Aksara.

Undang-Undang Republik Indonesia Nomor 20 Tahun 2003.

Zatulifa, M., Riswandi, Fitriawan, H., \& Akla. (2018). Application Based Android As A Development Of English Learning Media. IOSR Journal of Research \& Method in Education, 8(4), 66- 72. 